\title{
Using Integrated 2D and 3D Resistivity Imaging Methods for Illustrating the Mud-Fluid Conduits of the Wushanting Mud Volcanoes in Southwestern Taiwan
}

\author{
Ping-Yu Chang ${ }^{1, *}$, Shu-Kai Chang ${ }^{1}$, Hsing-Chang Liu ${ }^{2}$, and Shih Chung Wang ${ }^{3,4}$ \\ ${ }^{1}$ Institute of Applied Geoscience, National Taiwan Ocean University, Keelung, Taiwan, ROC \\ ${ }^{2}$ Disaster Reduction Research Center, Ching-Yun University, Jhongli, Taiwan, ROC \\ ${ }^{3}$ Department of Environmental Resources Management, Dahan Institute of Technology, Hualien, Taiwan, ROC \\ ${ }^{4}$ Department of Resources Engineering, National Cheng Kung University, Tainan, Taiwan, ROC
}

Received 26 March 2010, accepted 21 June 2010

\begin{abstract}
We conducted 2D and 3D looped resistivity surveys in the Wushanting Natural Landscape Preservation Area (WNLPA) in order to understand the relationships of the mud-fluid conduits in the mud volcano system. 2D resistivity surveys were conducted along seven networked lines. Two separate C-shape looped electrode arrays surrounding the volcano craters were used in the study. First, the two 3D looped measurements were inverted separately. Yet the inverted 3D images of the mudvolcano system were inconsistent with the landscape features suggesting that artifacts perhaps appeared in the images. The 3D looped data were then combined with the 2D data for creating a global resistivity model of WNLPA. The resulting 3D image is consistent with the observed landscape features. With the resistivity model of WNLPA, we further tried to estimate the distribution of water content. The results suggest that the 3D resistivity image has the potential to resolve the dual porosity structures in the mudstone area. Last, we used a simplified WNLPA model for forward simulation in order to verify the field measurement results. We have concluded that the artifacts in the 3D looped images are in fact shadow effects from conductive objects out of the electrode loops, and that inverted images of combined 2D and 3D data provide detailed regional conductive structures in the WNLPA site.
\end{abstract}

Key words: ERT, Resistivity, Mud volcano

Citation: Chang, P. Y., S. K. Chang, H. C. Liu, and S. C. Wang, 2011: Using integrated 2D and 3D resistivity imaging methods for illustrating the mud-fluid conduits of the Wushanting mud volcanoes in southwestern Taiwan. Terr. Atmos. Ocean. Sci., 22, 1-14, doi: 10.3319/TAO.2010.06.21.01(TT)

\section{INTRODUCTION}

Two-dimensional (2D) surface-based resistivity surveys have been used widely in different shallow subsurface explorations (e.g., Daily et al. 1992; Yang et al. 2002; Yang et al. 2005; Cassiani et al. 2006; Cheng et al. 2008 ). In some cases, the $2 \mathrm{D}$ sections have been combined to form reasonably accurate images of three-dimensional (3D) structures (e.g., Bernstone et al. 1997; Dahlin and Loke 1997); however, 3D techniques (Loke and Barker 1996; Slater et al. 2002) for resistivity surveys may have to be considered if one has to illustrate detailed subsurface structures in a strongly heterogeneous environment (Dahlin et al. 2002).

In this study, we attempted to use both $2 \mathrm{D}$ and $3 \mathrm{D}$ surface resistivity surveys to investigate the geometry of

\footnotetext{
* Corresponding author

E-mail:pingyuc@mail.ntou.edu.tw
}

the fracture systems in the Wushanting Natural Landscape Preservation Area (WNLPA). The WNLPA is in the thick Gutingkeng mudstone area. The self-healing of fractures filled with mud-fluids causes the mud fluid conduits to vary from time to time and makes it difficult to observe the connection of the fracture systems at the surface. In this particular area, we first conducted 2D resistivity imaging surveys between 2005 and 2007 (Chang et al. 2010) for monitoring the variation of the resistivity structures. From the results of 2D surveys, we learned that the fractures filled with mud fluids are very conductive 3D objects compared to the surrounding saturated mudstone and that their orientations may not be imaged correctly in 2D surveys owing to the shadow effect (e.g., Nimmer et al. 2008). We therefore conducted $3 \mathrm{D}$ resistivity imaging with the looped electrode arrays in order to take the complicated 3D structures into account. The looped arrays were placed surrounding the two major 
volcano craters to pick up as many signals from the main eruption conduits as possible. Because the 2D survey lines were aligned across the entire WNLPA and the 3D arrays were focused on the two major structures, we further combined the 2D and 3D measurements into a jointed data file and attempted to invert them together for illustrating the fracture systems in the WNLPA.

Last, we tried to estimate the water content distribution of the WNLPA from the resistivity-"water content" relationships constructed through a lab test. Soil samples were collected near the site and tested with the beaker test. Through the 3D resistivity model, we tried to illustrate the dual-porosity structures (i.e., the vertical fractures filled with mud fluids and the horizontal groundwater surface of saturated pore media), and to construct a conceptual model of the fracture systems in the WNLPA.

\section{SITE DESCRIPTION}

In southwestern Taiwan, abundant mud volcanoes have erupted on land and offshore owing to intensely compressed tectonic environment and to thick mud deposits (Shih 1967; Huang et al. 1992; Liu et al. 1997). Most of the mud volcanoes on land are related to geological structures and are distributed along the axis of the Gutingkeng anticline and the Chishan fault (Wang 1988). Of the mud volcano systems identified in southwestern Taiwan, WNLPA, is located in the Yanchao district near the Chishan fault in Kaohsiung County (Fig. 1). In the WNLPA, fluids and gases erupt from the fissures in the thick Pleistocene Gutingkeng mudstone (Keng 1981) and form distinct volcano-like landscapes (Fig. 2a). The gas in mud volcanoes is believed to have close relationships with the decomposed organic matter of the mudstone formation. You et al. (2004) suggest that fluids emanating from Taiwanese mud volcanoes were originally marine pore waters that mixed with meteoric water or that underwent surface evaporation during the recharge and discharge processes.

The mud volcanoes in the WNLPA are located in a $200-\mathrm{m} \times 150-\mathrm{m}$ plateau. There were originally three main mud-volcano craters: craters $\mathrm{B}, \mathrm{S}$ and $\mathrm{H}$ in the plateau (Fig. 2b). A new parasite mud-volcano cone was formed beside the $\mathrm{S}$ crater after the Pingtung earthquake in December of 2006. The WNLPA's unique geomorphic features have led the government to designate the site a natural landscape preservation area in the county. Perturbation is prohibited in the area and thus had made it difficult to drill or to collect subsurface samples for further investigation of the fracture systems.

\section{THE NETWORKED 2-D RESISTIVITY SURVEYS}

We conducted 2D resistivity imaging profiling surveys along seven survey lines across the WNLPA and then along two lines once a month between July 2007 and April 2008 to monitor the resistivity variations. We selected Dipole-dipole and Wenner arrays for the surveys because they provide lateral and vertical coverage of the subsurface. For the surface electrical resistivity imaging profiling (RIP) measurement, we used the LGM 4-point Light hp resistivity meter with the Active electrode (ActEle) system (Lippmann 2005). We used a maximum number of 13 for the dipole separations and the dipole lengths in the surveys. The data were measured repeated and stacked, we used a 3\% threshold for removing bad measurements. To construct a geology model of the WNLPA, we performed data acquisition with 40 electrodes spaced every $1.5-\mathrm{m}$ along the south-to-north lines (lines C, D, E, and F in Fig. 2b), and with 20 similarly spaced electrodes along the east-to-west lines (lines X, Y, and $\mathrm{Z}$ in Fig. 2b). The collected $2 \mathrm{D}$ resistivity data were inverted with EarthImager ${ }^{\mathrm{TM}}$ 2D (AGI 2009).

Figure 3 shows the inverted resistivity of the northsouth $\mathrm{C}, \mathrm{D}, \mathrm{E}$, and $\mathrm{F}$ lines and the east-west $\mathrm{X}, \mathrm{Y}$, and $\mathrm{Z}$ lines. Symbols B and $\mathrm{S}$ indicate the projected positions of the mud-volcano craters. In general, the inverted resistivity ranged from 1 to $12 \mathrm{Ohm}-\mathrm{m}$ for the mudstone in the $\mathrm{WN}$ LPA. The region between the ground surface and 2 - 3 meter in depth is more resistive than the underlying region and implies an unsaturated surface layer in the area. With regard to high-resistivity regions (regions whose resistivity is over $10 \mathrm{Ohm}-\mathrm{m}$ ), lines $\mathrm{E}$ and $\mathrm{F}$ exhibited resistivity that was greater than the resistivity in the $\mathrm{C}$ and $\mathrm{D}$ lines. And again regarding high-resistivity regions, line $\mathrm{Z}$ exhibited resistivity that was greater than the resistivity in lines $\mathrm{X}$ and $\mathrm{Y}$. The unsaturated regions along the $\mathrm{E}, \mathrm{F}$, and $\mathrm{Z}$ lines may constitute a relative "drier zone" than the rest of the WNLPA (Chang et al. 2010). It should be noted that we barely

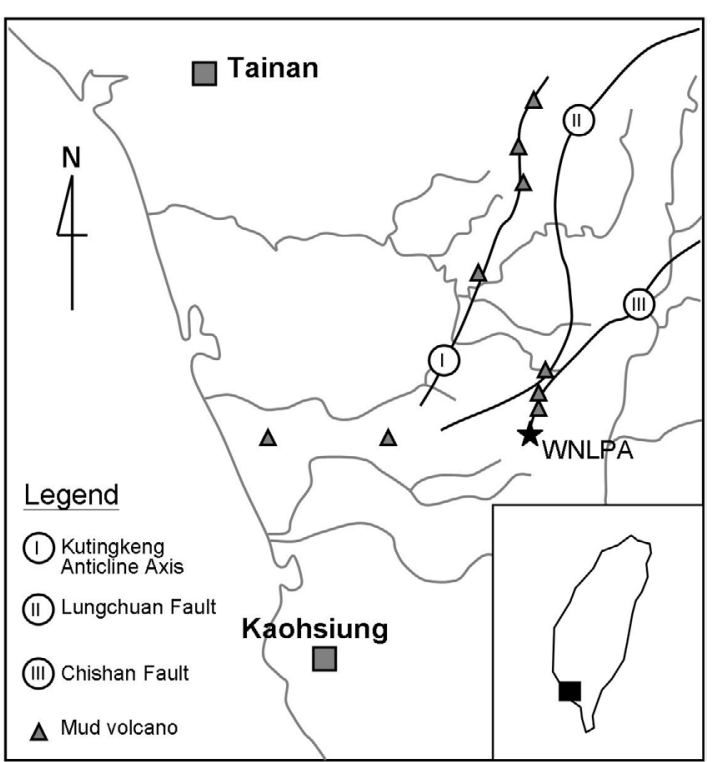

Fig. 1. The locations of the mud volcanoes in southwestern Taiwan. 
observed the low resistivity regions that penetrated the unsaturated surface zone vertically as we expected, except for that in profile $\mathrm{Z}$ in Fig. 3. The locations of the low resistivity regions are also inconsistent with the locations of the projected volcano craters in most of the profiles in Fig. 3.

\section{THE 3D LOOPED SURVEYS}

Because the cone-shaped craters prevented us from laying a zigzag 3D grid survey across the field, we planned to deploy looped electrode arrays surrounding the two major craters for $3 \mathrm{D}$ resistivity measurements in order to gain stronger responses from the major fractures. The looped electrode arrays were laid in a counter-clockwise, centerout configuration (Fig. 2c) for the B and S craters, separately. With a total of 80 electrodes used in the research, we imaged the subsurface structure down to about $4 \sim 5 \mathrm{~m}$ in depth with an electrode spacing of 2-m. Having adopted a 2D auto-rolling collection system for the 3D surveys, we chose the Dipole-dipole and Wenner data-collection sequence for the measurement. And the set-up of the data collection sequence is similar to that in the $2 \mathrm{D}$ surveys.

We inverted both the 3D resistivity data of the $\mathrm{B}$ and $\mathrm{S}$ looped arrays by using the EarthImager ${ }^{\mathrm{TM}} 3 \mathrm{D}$ software (AGI

(a)

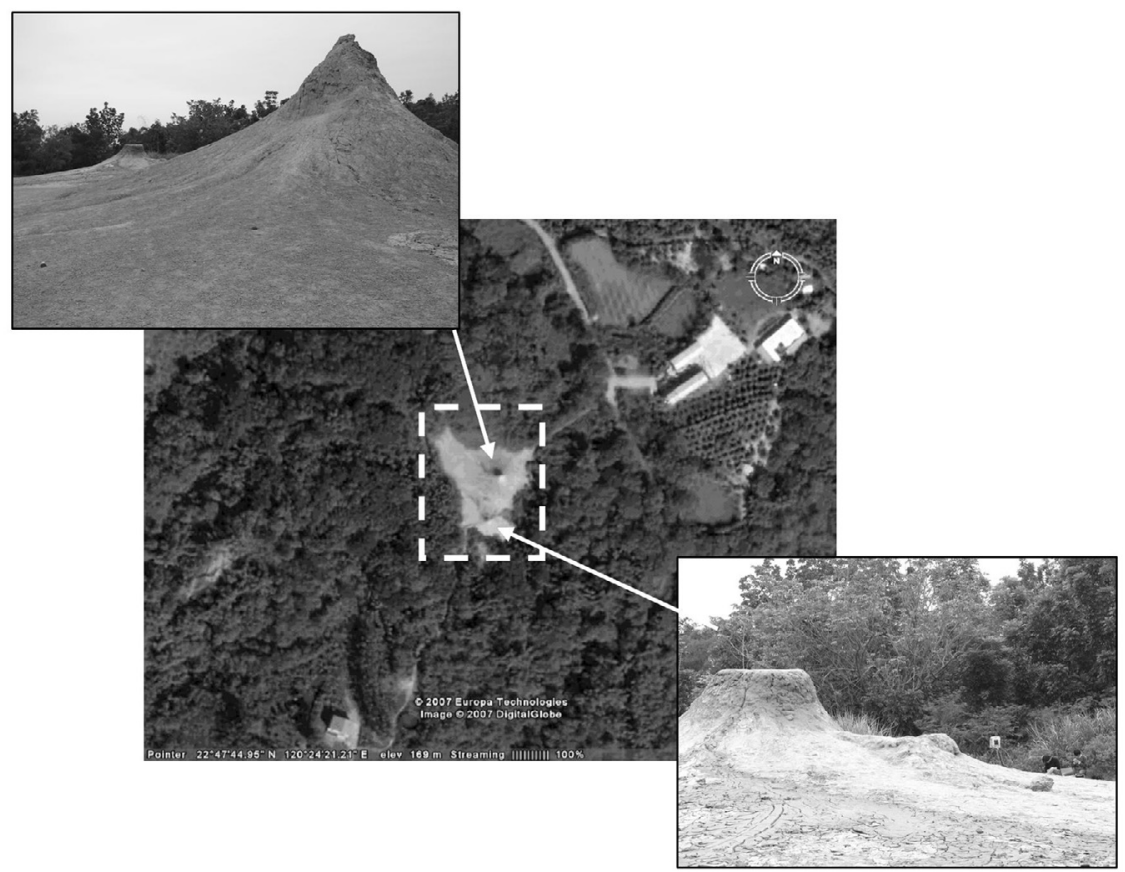

(b)

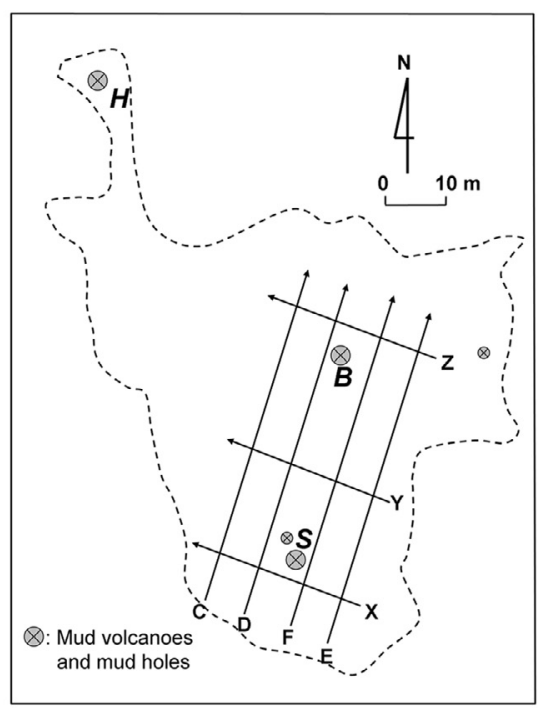

(c)

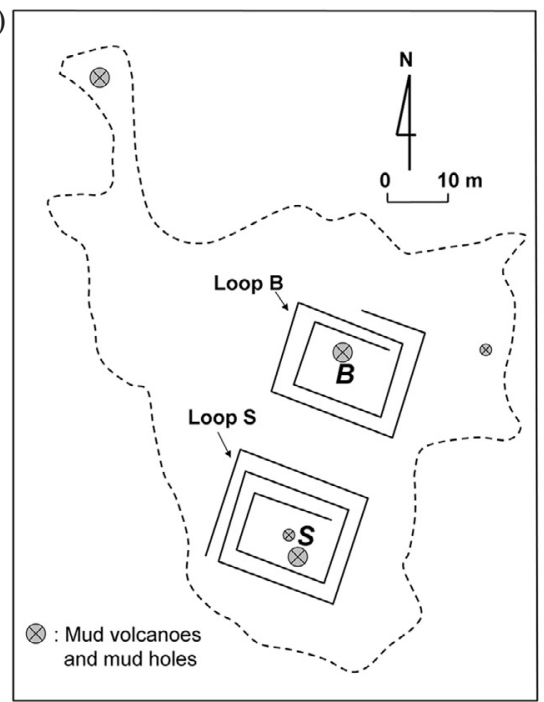

Fig. 2. (a) Pictures of the mud volcanoes and mud holes in the Wushanting Natural Landscape Preservation Area. (b) Maps of the WNLPA and the configurations of 2D networked survey lines (Dashed line indicate the boundary of the WNLPA). (c) The configurations of 3D looped electrode arrays. 
(a)
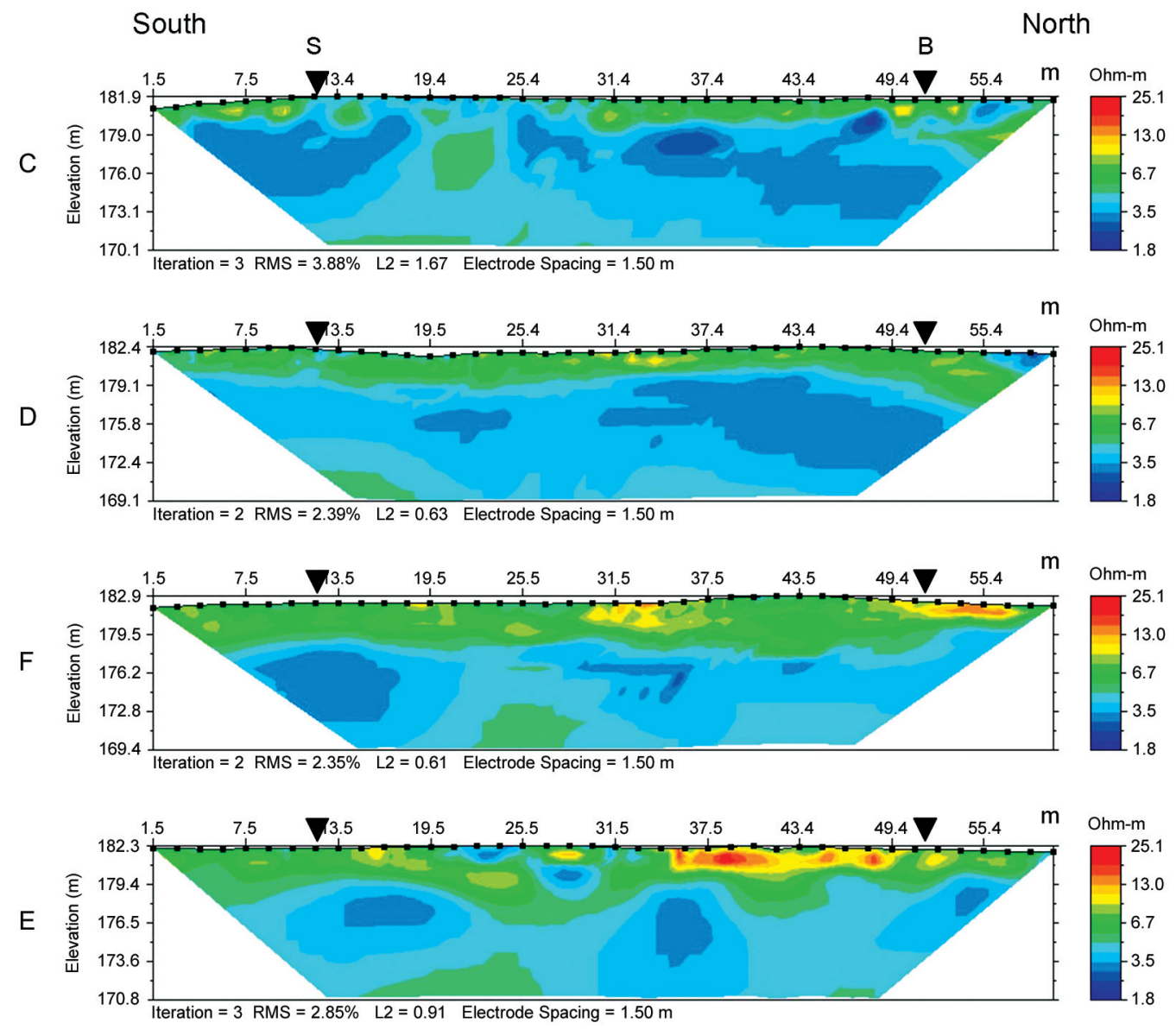

(b)
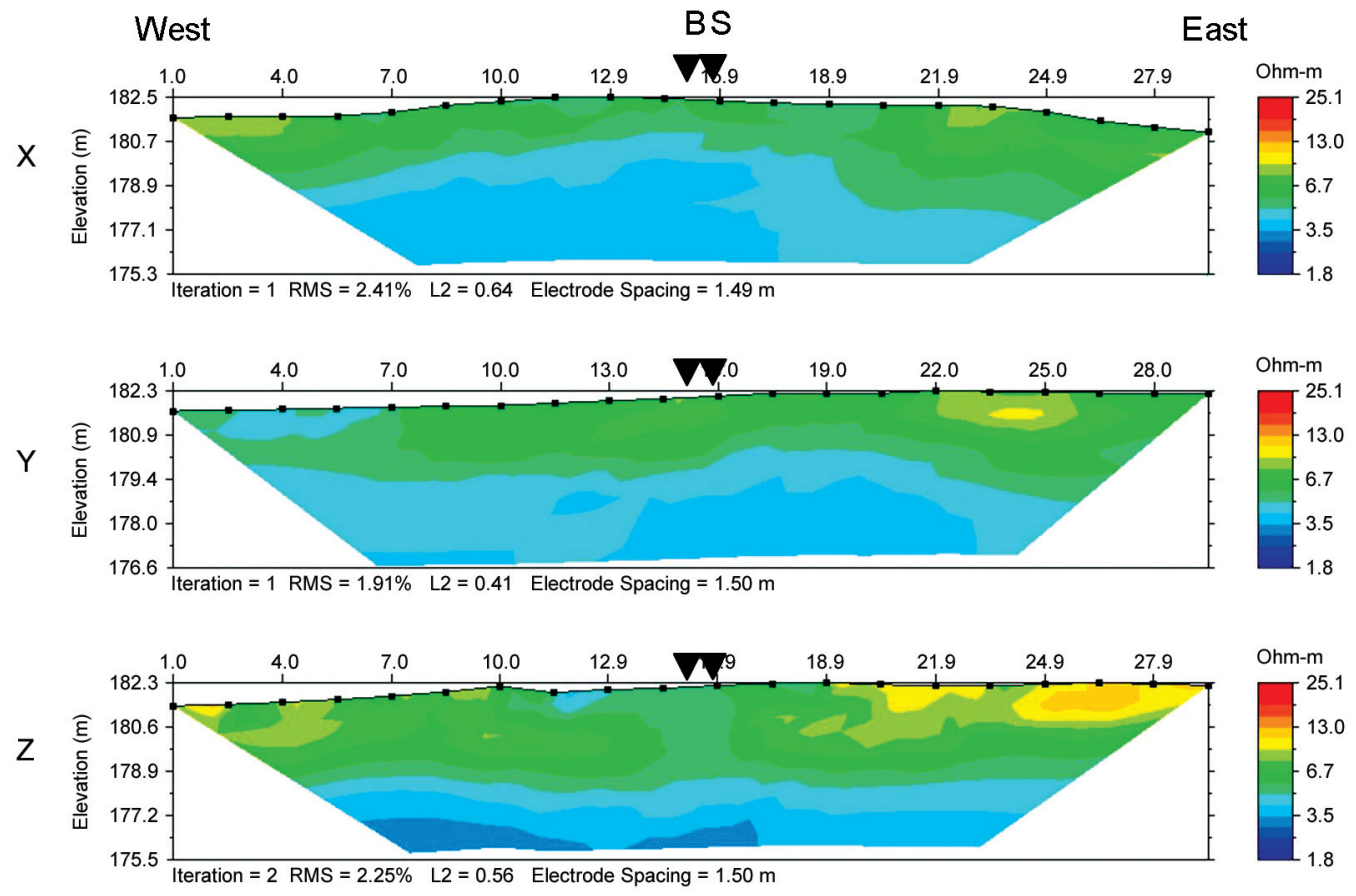

Fig. 3. The results of the $2 \mathrm{D}$ resistivity surveys (B and $\mathrm{S}$ indicate the projected positions of the mud volcanoes $\mathrm{B}$ and $\mathrm{S}$, respectively). 
2008). EarthImager ${ }^{\mathrm{TM}} 2 \mathrm{D}$ and $3 \mathrm{D}$ software employs iterative algorithms of forward simulation and inversion schemes to estimate the subsurface resistivity structures. Dirichlet and mixed boundary conditions (Dey and Morrison 1979) were implemented. The matrix system was iteratively solved according to a conjugate gradient method. The aforementioned software also features an adjustable smoothing constraint in the inversion scheme. The smooth model inversion algorithm was originally described in Constable et al. (1987) and DeGroot-Hedlin and Constable (1990). Although Loke et al. (2003) suggest that the blocky model inverted with the L1 norm is more suitable than the smooth model for fracture detection. We found that the fractures filled with fluids in the mudstone area do not have sharp boundaries to the surrounding sediments, instead, a muddy smearing zone surrounding the major fractures are commonly found. Hence neither the small smooth constraint nor L1 norm yields a reasonable model for the WNLPA case. In addition, the inversion scheme is more sensitive for the spaces near the surface electrodes and less sensitive for spaces deeper and farther away from the electrodes. Without proper smoothing of the model to account for this sensitivity difference, the inverted model will show conductive regions congregated around the surface survey lines. Therefore, in 3D inversion it is important to select a proper smooth constraint that gives reasonable inverted model on the basis of trial-and-error.

We found that there are more very high and very low apparent-resistivity measurements among the 3D data than there are in the previous 2D data because of the complicated geometry of electrode configurations. In our previous $2 \mathrm{D}$ resistivity surveys, we found that most of the measured

(a) Loop B
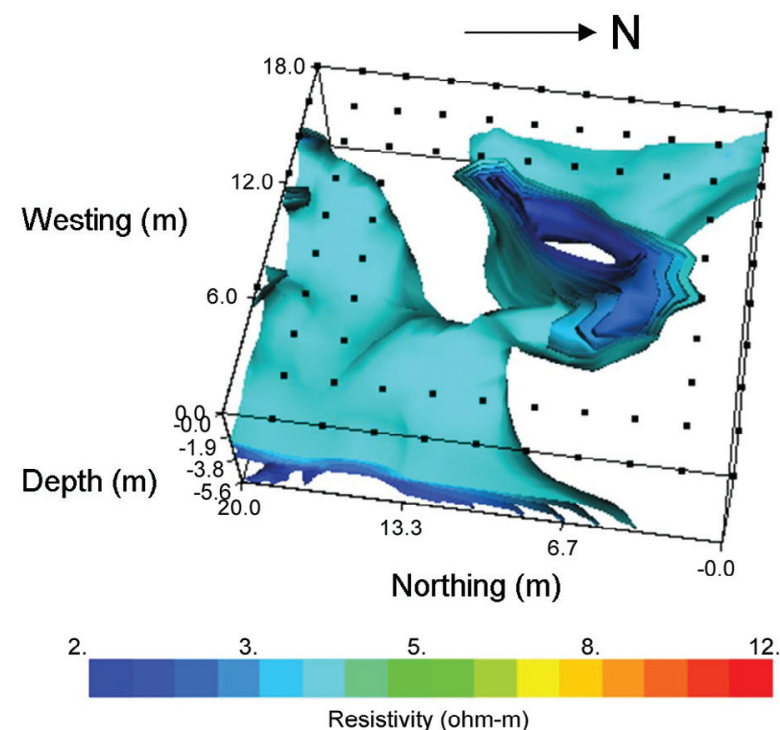

apparent-resistivity values (99.7\% of 2318 data along 7 different survey lines) are in a range between 1 and $12 \mathrm{Ohm}-\mathrm{m}$. To sort out the noisy data, we adopted a low-pass filter of $12 \mathrm{Ohm}-\mathrm{m}$ and a high-pass filter of $1 \mathrm{Ohm}-\mathrm{m}$ in the preprocessing procedure. Figures $4 \mathrm{a}$ and $\mathrm{b}$ show the inverted images of the B and the S craters, individually, collected in April 2008. To illustrate the fractures filled with mud fluids, we show the resistivity isosurfaces of $4.2,3.7,3.4$, and $2.4 \mathrm{Ohm}-\mathrm{m}$ only in Fig. 4. Figures $4 \mathrm{a}$ and $\mathrm{b}$ suggest that a conductive region can be identified under the mud volcanoes B and S, individually. The volume mud-volcano S's conductive region in Fig. $4 \mathrm{~b}$ is much larger than the mudvolcano B's corresponding volume in Fig. 4a. Because mud volcano $\mathrm{S}$ had been more active than mud volcano $\mathrm{B}$, the $3 \mathrm{D}$ resistivity imaging surveys suggest that mud volcano $S$ would have a larger conduit system than mud volcano B. Although the 3D resistivity images resolved the conductive body in the looped arrays, we found that the locations of the two conductive regions were inconsistent with the positions of the two mud volcano outlets. The findings suggest that the 3D looped arrays may not resolve the structure correctly and that some artifacts perhaps were present in the images. Thus a further study of the accuracy of 3D images is needed.

\section{GLOBAL RESISTIVITY IMAGES OF THE WNLPA}

To show a global 3D resistivity image of the WNLPA, it is feasible to combine the 2D networked and 3D looped measurements for the inversion. The idea of the approach is that the networked 2D surveys have a simpler array

\section{(b) Loop S}
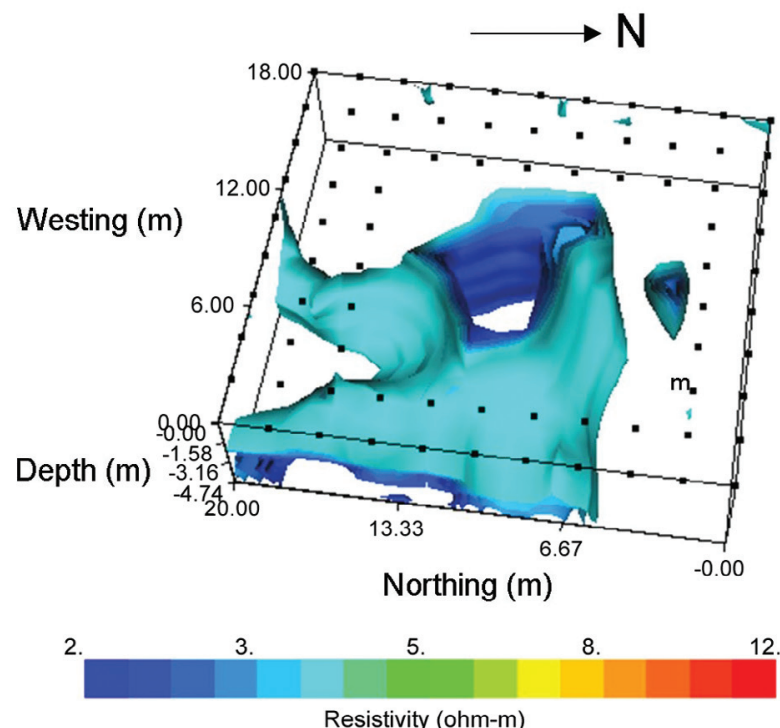

Fig. 4. The inverted results of the 3D resistivity surveys of (a) the loop B and (b) the loop S. To illustrate the fractures filled with mud fluids, we show the resistivity isosurfaces of $4.2,3.7,3.4$, and $2.4 \mathrm{Ohm}-\mathrm{m}$ only. 
geometry, lower noises, and deeper exploration depths due to a longer array length, and the 3D measurements could provide focused information about the conductive channels under the two major craters. Notably, our study's 2D and $3 \mathrm{D}$ resistivity data had not been collected at the same time. We used the 2D and 3D data for the inversion only to help in constructing a model that could summarize the connections of oversaturated mud conduits. One may argue the 2D and 3D data are not measured in the same period and can not be used together. The saturated zone in the WNLPA is observed to have no obvious variation over $5 \mathrm{Ohm}-\mathrm{m}$ from our previous long-term resistivity observation (Chang et al. 2010). Major resistivity variations are found to be located in the unsaturated zone. Therefore to construct a quasi-static model to overview the connections of oversaturated mud conduits, we believe that the previous 2D data is still available to provide valid information although they are not collected at the same period.

Figure 5a shows the resistivity image from the inversion results of combined 2D and 3D data and networked 2D data, respectively. The RMS of the inversion model reached $8.3 \%$ after 3 iterations in the inversion of combined $2 \mathrm{D}$ and $3 \mathrm{D}$ data and $5.0 \%$ after 4 iterations in the inversion of $2 \mathrm{D}$ data. Unlike Fig. 4a's 3D resistivity image portraying the conductive-edge structures, in Fig. 5a image shows clearly a single vertical conductive channel under mud volcano crater B. In addition to the vertical conductive channel, we observed some small vertical conductive structures off the 3D loop of mud volcano B as presented in Fig. 5a. Moreover, we noticed that the global resistivity image resolves

(a)
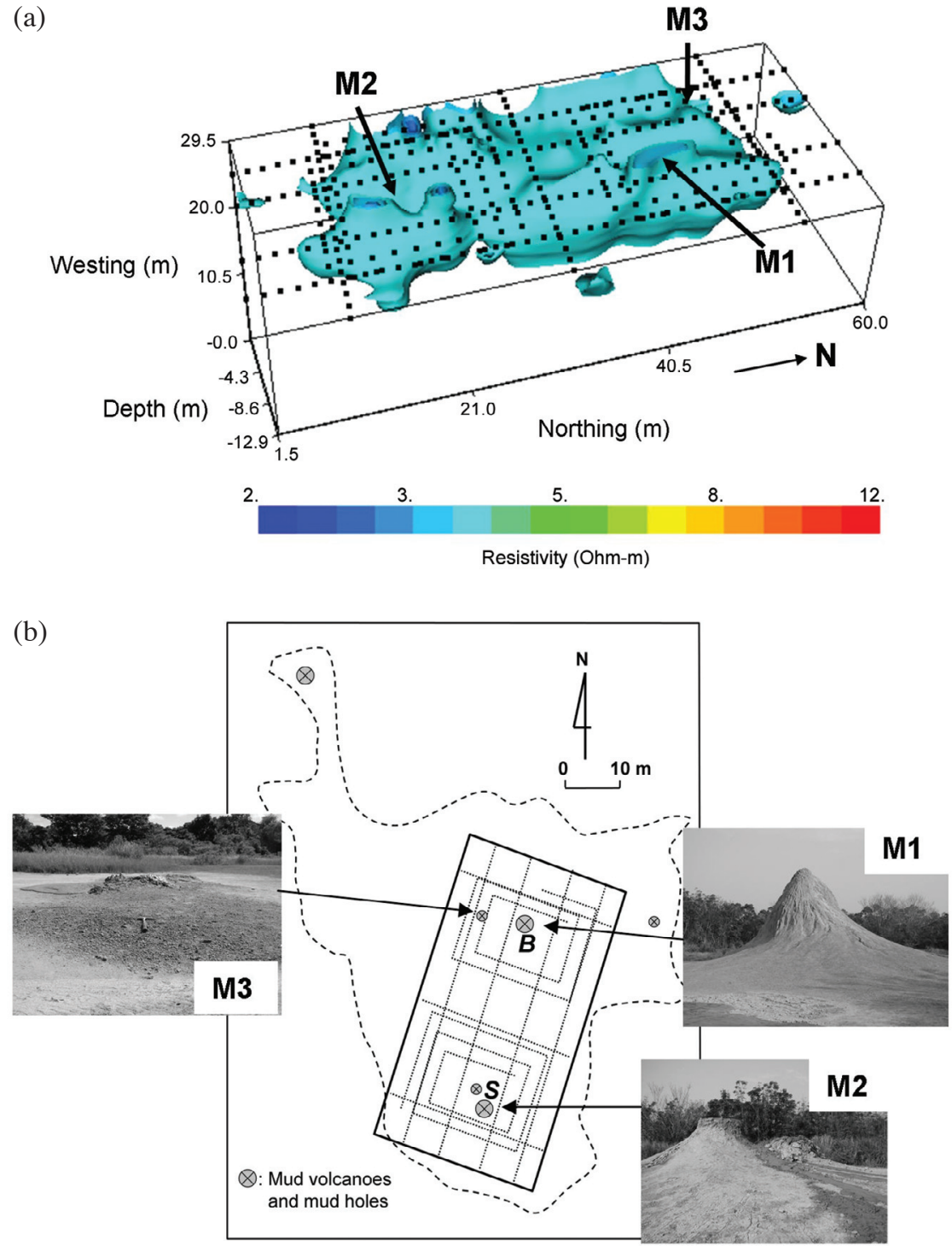

Fig. 5. (a) An oblique view of the inverted image of combined 2D and 3D data. Only low-resistivity regions $(<4.2$ Ohm-m) are shown here to illustrate the possible fractures filled with conductive mud fluids. (b) The map of the integrated 2D and 3D surveys in the WNLPA. Pictures M1 and M2 show the observed landscape features on the ground. M3 shows the location of a new mud-volcano crater later (in 2008) observed on the surface. 
two separate conductive channels in Fig. 5a at mud volcano $\mathrm{S}$, a finding that is consistent with our observations at the site (as seen in Fig. 5b). A comparison between images in Figs. 4 and 5a suggest that the 3D image from the looped surveys did not resolve the dual-channel structure of mud volcano S correctly. On the other hand, Fig. 4b shows no vertical conductive channel at the same location although it illustrates a similar distribution of conductive body to Fig. 5a. The 3D image inverted from the looped measurement in Fig. 4b shows only a broad conductive region in the center instead of two conductive channels.

Because the WNLPA, designated a preservation site, receives protection from the county government, researchers have difficulty collecting core samples to verify directly the inverted images of the 3D looped surveys and the image of the composite 2D and 3D data. Fortunately, the distinctive landscapes such as the positions of the mud holes and the mud-volcano craters are the good indicators that can help us to verify the resistivity images. In Figs. $5 b$ and $6 c$, the positions of the craters and mud holes are consistent with the conductive mud conduits illustrated. However, 2D resistiv- ity images in Fig. 6a show no conductive channels at the locations of the craters B and S. The findings suggest that the distance between the networked 2D surveys lines are too far to resolve the structures in detail, and the looped 3D data should provide additional data to resolve the structures.

In addition, the evolution of the mud-volcano systems presents other evidence that one can use to check the accuracy of the inverted images. For instance, the vertical low-resistive structure located at coordinate $(40.5 \mathrm{~m}, 23 \mathrm{~m})$ in Fig. 5a featured no surface-level outcrop at the time we completed the survey (i.e., in April 2008). In October 2008, we observed a new surface-level mud hole, which became a small mud volcano by July 2009, as Fig. 5b shows. The findings confirm the accuracy of the composite 3D resistivity image. To further verify the resistivity image, a GPR survey was conducted in July of 2009 along Line F shown in Fig. 2b. We used Zond12e system and antennas with a central frequency of $38 \mathrm{MHz}$. The GPR raw data were processed using band-pass filtering, static correction, and background removal to highlight the fractures that truncating or disturbing horizontal reflectors. The radargram is shown in

(a)

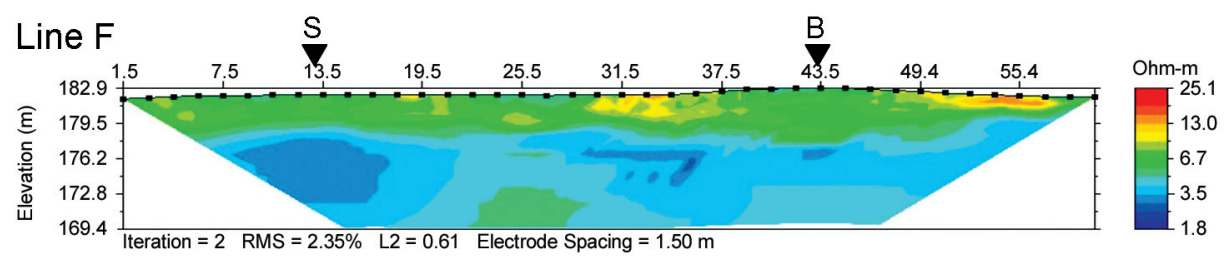

(b)

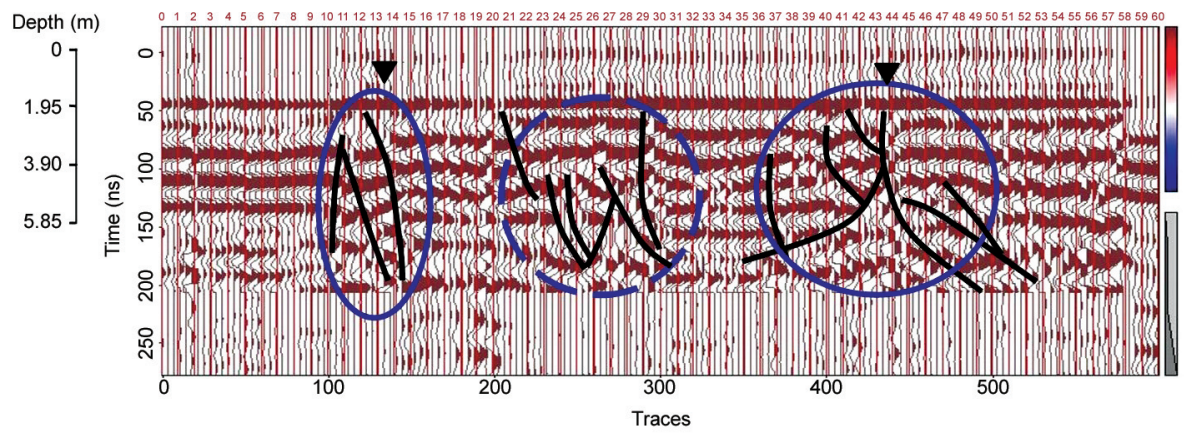

(c)

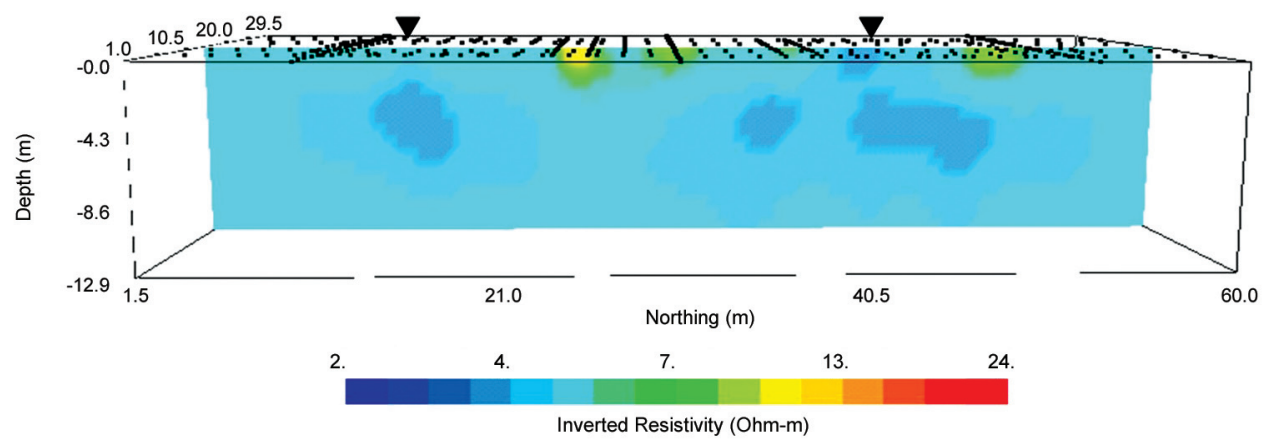

Fig. 6. (a) The 2D inverted resistivity image of line F. (b) The GPR radargram collected along line F. Three major fracture systems are identified and highlighted with dashed and solid blue circle lines (The vertical scale represents the two-way travel time). (c) The 3D slice of jointed inverted image of the profile along line F. The horizontal distance is in meters in all three images. 
Fig. $6 \mathrm{~b}$ and the two-way travel time is converted into vertical depth according to the velocity estimation results in Chow et al. (2006).

Compared with the 2D inverted image, the 2D slice of the image from combined $2 \mathrm{D}$ and $3 \mathrm{D}$ data suggests a better resolution for the fracture zones marked by solid blue circles. However, neither 2D nor 3D inverted image resolve the fracture zone marked by the dashed blue circle between the two mud volcano craters. In fact, this fracture zone marked by the dashed bluecircle just appeared in 2009, and is resolved in our monitoring work with similar time-lapse $3 \mathrm{D}$ resistivity images.

\section{ESTIMATING THE DISTRIBUTION OF WATER CONTENT FROM THE 3D RESISTIVITY IMAGES}

We took several soil samples around the perimeter of the WNLPA site (because no sampling is allowed inside the protection zone) and conducted a laboratory "beaker test" in order to create circumstances that would enable us to identify the relationships between the water-content and the resistivity. Soil samples were heated for 24 hours in an oven at $105^{\circ} \mathrm{C}$ and then were packed, in equal parts, into several 1-liter beakers and weighed. We maintained at least $6 \mathrm{~cm}$ of thickness between the bottom of the beakers and the sample surface to ensure the absence of boundary interruptions. Electrodes were placed on the sample surface to measure the resistivity. We added various volumes of water into the beakers and sealed the top of the beakers for a day. Local tap water from the nearby local reservoir is used in the experiment. Then the beakers were weighed and the resistivity was measured according to the Wenner array with surface electrodes spaced 2-cm from one another. The French-made Chauvin-Arnoux C.A 6460 Earth \& Resistivity Tester was used for measuring the resistivity of the samples. Last, the soil samples were weighed again so that the study would correct for evaporation (loss of water) during the measurements. The beaker test provides a quick way to build the resistivity-"water content" relationships in the laboratory. In addition, the test enabled us to measure the oversaturated condition easily.

Though the WNLPA is located in a mudstone area, the grain-size analysis shows that soil samples contained $4.0 \%$ clay, $67.1 \%$ silt, and $28.9 \%$ sand. Researchers have proposed various empirical and theoretical equations to describe the relationships between water content and measured bulk resistivity for soils and rocks, an example being Archie's empirical equation (Archie 1942). In the current study, we adopted a single power-law function similar to that of LaBrecque et al. (2002). The relationship between bulk resistivity and water content can then be described as

$\rho=a \cdot \theta^{-b}$ where $\rho$ is the bulk resistivity, $\theta$ is the volumetric water content, and $a$ and $b$ are the empirical constants that were determined through a comparison of measured resistivity to water content in the beaker test. Noting that parameters $a$ and $b$ might vary between the lab-scale test and the field experiment, we used only the empirical relationships, built in the beaker test, to conduct a rough evaluation of the water content's variation range at WNLPA. Here, we determined that $a=3.5$ and $b=0.81$ from the unsaturated results of the beaker test shown in Fig. 7, with an R-square error of 0.96 .

With Eq. (1), we were able to estimate the water-content distribution from the resistivity image. Figure 8 shows the distribution of the water content from the resistivity measurements in WNLPA. Figure 8 shows that an undulating horizontal groundwater table (i.e., the surface boundary between the vadose zone and the saturated regions) is located at a depth of 2- to 3-m. This same figure also illustrates several vertical oversaturated structures, representing the fissures filled with mud fluids which penetrated the groundwater table surface and emerged on the surface. Note, not only the smoothing constraints in the inversion give rise to errors in the estimated water content, but also the nature that resolution of the surface resistivity methods decreased just as when with increasing exploration depths yields errors in the estimated water content. Hence we only portrayed the vertical oversaturated regions as well as the groundwater table here to show the potential of estimating water-content distribution with the 3D resistivity image.

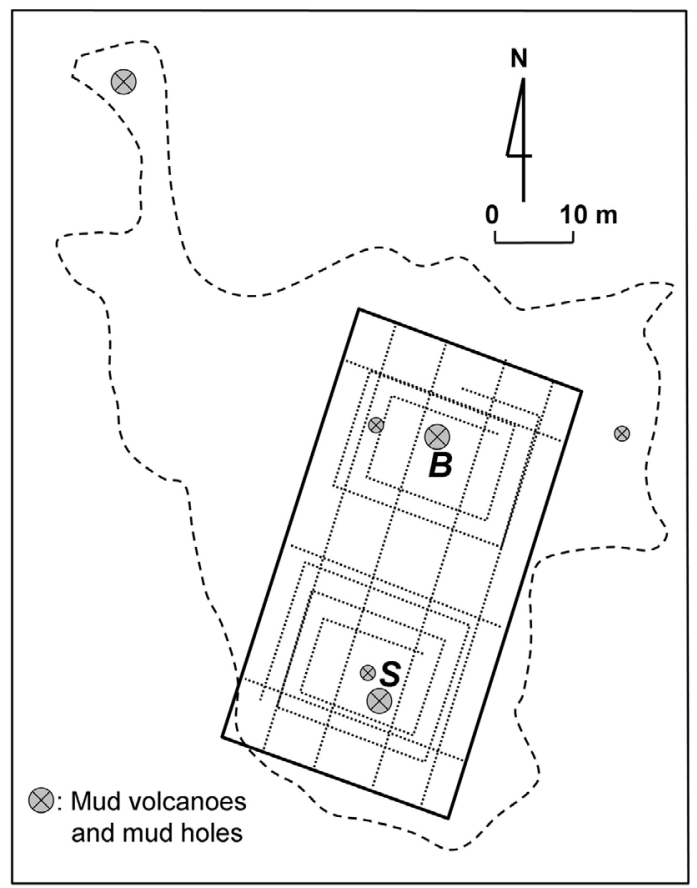

Fig. 7. The relationships between the water content and the measured resistivity for the mud samples collected at the area adjacent to the WNLPA. 
(a)

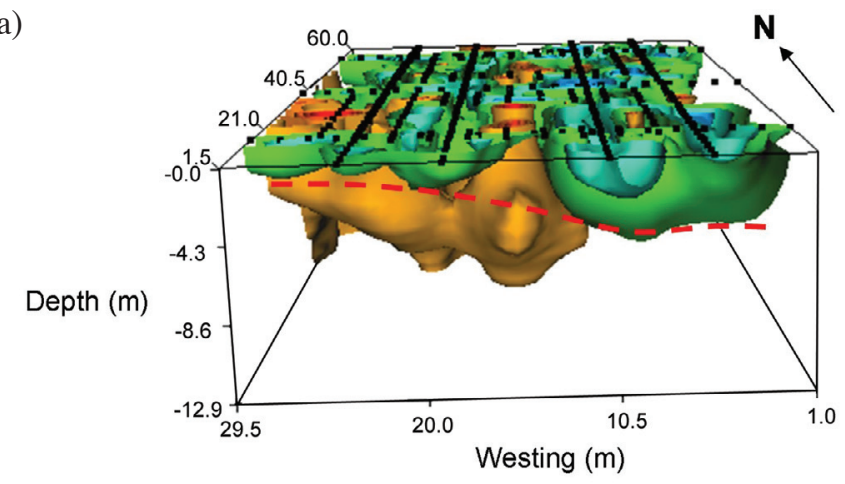

(b)

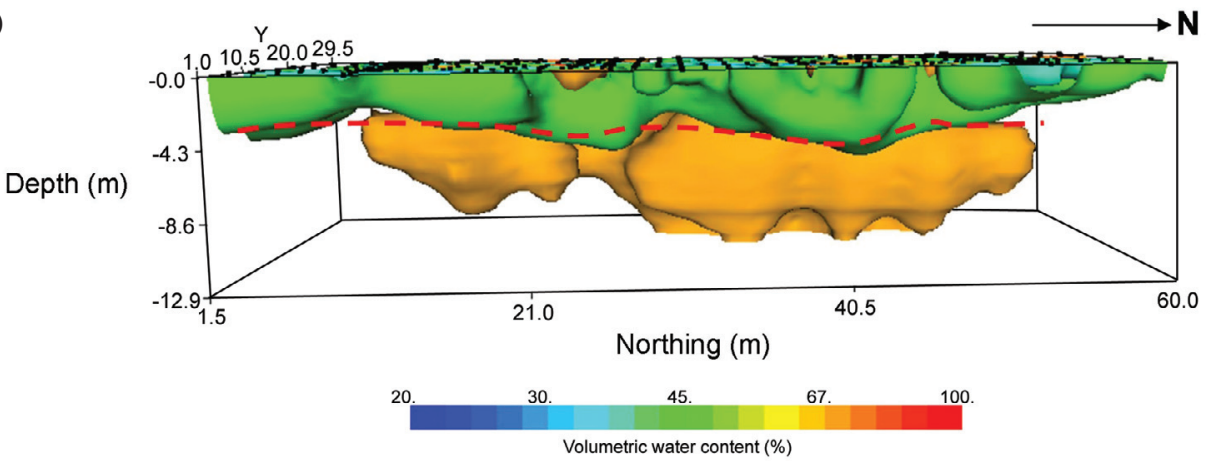

Fig. 8. (a) The front view and (b) the side view of the distribution of estimated water content. We show only the oversaturated (over $60 \%$ ) and saturated (42\%) isosurfaces in the graph to show the distribution the mud-fluid conduits and saturated porous media. Dashed red line indicates the possible boundary of saturated and unsaturated zones (i.e., the groundwater surface).

\section{FORWARD MODELING OF THE 3D RESISTIV- ITY SURVEYS}

In the previous section, we have found that the inverted resistivity image of combined $2 \mathrm{D}$ and $3 \mathrm{D}$ data was consistent with the landscape features and the GPR results. However, the difficulty in getting permission to drill cores in WNLPA for the purposes of directly verifying these resistivity images means that the evidence from the landscape and the GPR radargram is limited in scope. Hence we tried to examine the images by using forward modeling in combination with the resistivity model that we had constructed according to the previous WNLPA-related results. The forward simulation was conducted with the EarthImager ${ }^{\mathrm{TM}} 3 \mathrm{D}$ (AGI 2008) software.

We arranged the electrode arrays, including seven 2D line arrays and two 3D looped arrays, at the surface just as we had arranged in WNLPA. In the simplified WNLPA model (Figs. 9a and b), we assigned a resistivity of $1 \mathrm{Ohm}-\mathrm{m}$ to the conductive conduits filled with mud fluids, and a resistivity $5 \mathrm{Ohm}-\mathrm{m}$ to the background saturated mudstone. Two vertical conductive structures were placed at the location of the B and S craters, and they were connected with each other by a horizon fracture that did not crop out at the surface, in contrast to the 3D resistivity image. We imitated the parasite mud-volcano of the $\mathrm{S}$ crater by splitting the conductive structure of $\mathrm{S}$ volcano into two small conductive structures near the surface in the model. In addition, two vertical conductive structures were located out of the two looped arrays to represent the structures found in the field surveys. Dahlin (1996) suggests that a noise level of $3 \%$ is common in modern multi-electrode resistivity surveying. To represent a higher noise level as in the WNLPA, we assigned a 5\% random error to the forward simulations.

Figure 10a shows the inverted image of the forward modeling from only the 2D networked line surveys, and Fig. 10b shows the inverted image from data of combined 2D networked and 3D looped surveys. Both of the images suggest that the resistivity imaging surveys can correctly detect the conductive structures in a heterogeneous environment such as the WNLPA even at a 5\% random-error level. Figure 10b shows that the images of combined 2D and 3D data had a good resolution regarding the parasite structure at mud volcano $\mathrm{S}$. In contrast, Fig. 10a shows only a vertical conductive structure, rather than the two split conduits at the mud volcano $\mathrm{S}$. This contrast suggests that although the 2D networked measurements already imaged the conductive conduits well, the use of two 3D looped surveys should yield additional information that would help to better resolve the detailed conductive structure, such as the split two channels.

We have found that the inverted images of the 3D looped measurements are inconsistent with the landscape 
(a)
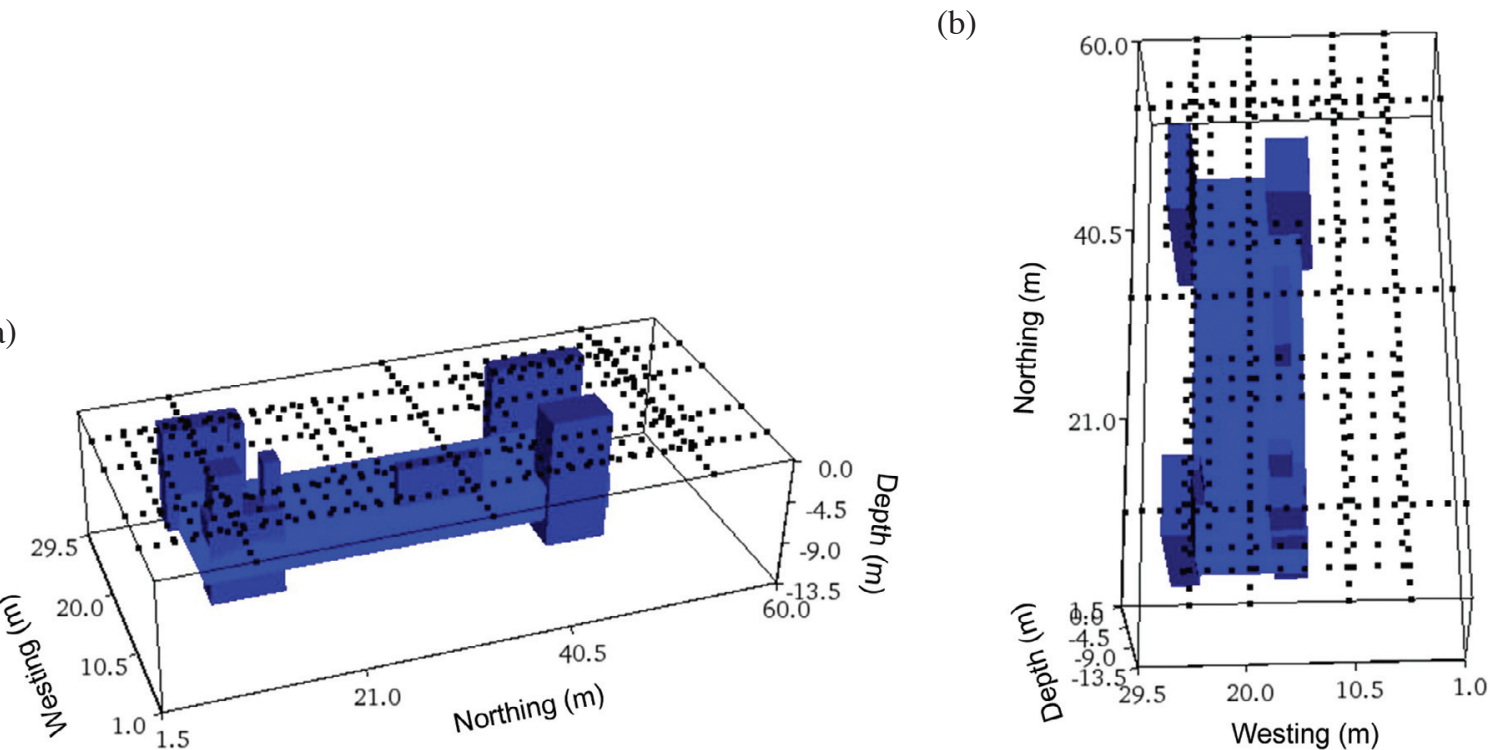

Fig. 9. (a) The oblique view of the resistivity model for the forward simulations of the WNLPA. The resistivity of low conductive conduits is $1 \mathrm{Ohm}-\mathrm{m}$ and the background resistivity is $5 \mathrm{Ohm}-\mathrm{m}$. (b) The vertical view of the resistivity model for the forward simulations of the WNLPA.

(a)

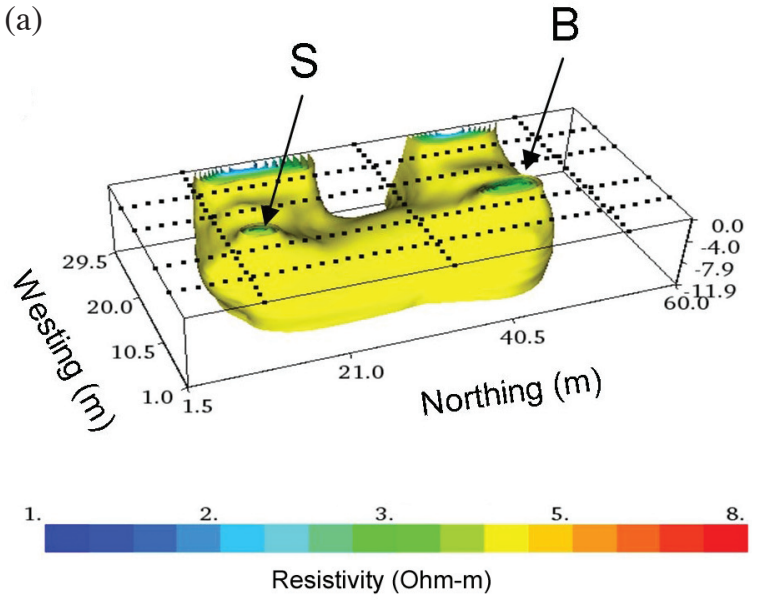

(b)
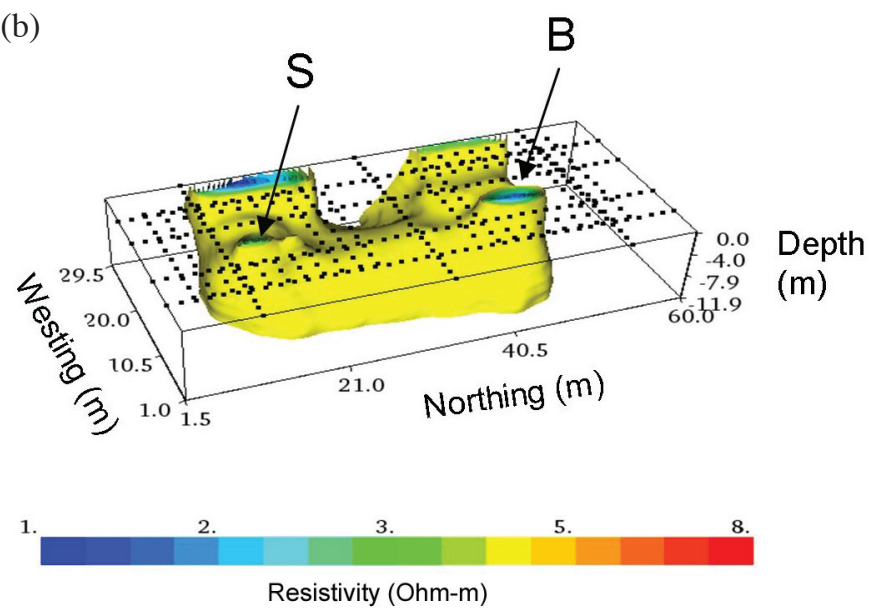

Depth

(m)

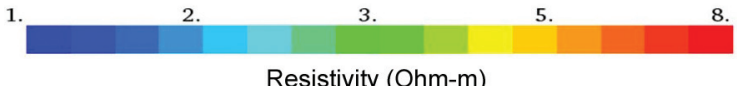

Resistivity (Ohm-m)

(m)

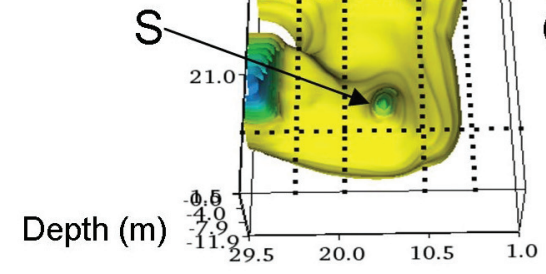

Northing

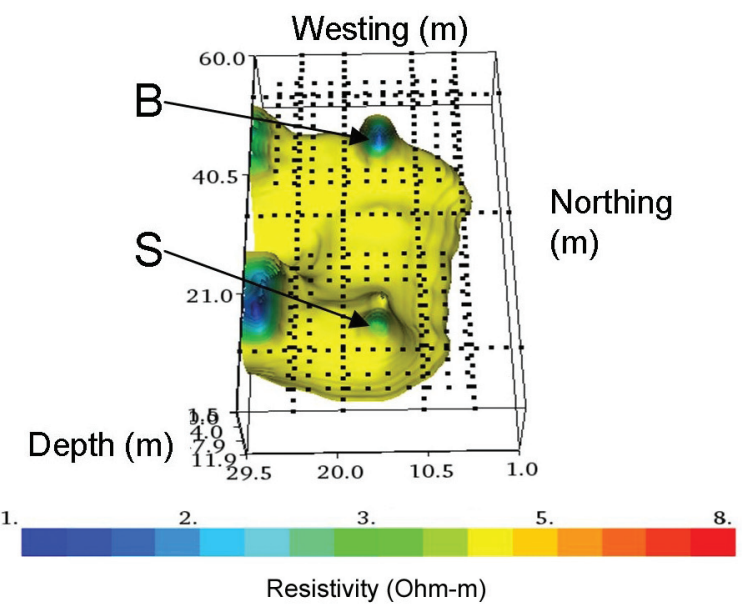

Fig. 10. (a) An oblique view (left) and vertical view (right) of the image inverted with only the networked 2D measurements from the forward simulations. (b) An oblique view (left) and vertical view (right) of the image inverted with the 2D and 3D looped measurements. Low-resistivity regions $(<4.5 \mathrm{Ohm}-\mathrm{m})$ are shown here to highlight the regions with conductive structures. 
features in our field measurements. To examine whether or not the images of 3D looped measurements contain artifacts as we thought, we inverted the simulated data of loops $\mathrm{B}$ and S, separately from the 3D looped measurements. Figures $11 \mathrm{a}$ and $\mathrm{b}$ are the inverted images of only the data of $3 \mathrm{D}$ looped surveys at the B and S craters, individually. In contrast to the original model in Fig. 9, a vertical conductive artifact was observable in the images of loop S (marked with the red circle in Fig. 11b). On the other hand, no obvious artifacts are found in the image of Loop B (Fig. 11a). The difference of the input models of Loops B and $\mathrm{S}$ is that the lateral vertical conductive structure is right on the electrode loop for mud volcano $\mathrm{B}$, but the similar structure is out of the electrode loop for mud volcano S. The findings suggest that the artifacts are likely the shadow effects from the structures outside the 3D arrays. Compared with the results in WNLPA, we also found that the shapes of conductive regions are inconsistent with the observation. As a result, we concluded 3D looped arrays may be affected by the structures out of the electrode loops and not resolve the structure correctly. Therefore, caution should be taken if there are complicated 3D resistivity structures in the field and if researchers are conducting only 3D surveys that cover a limited area.

In addition, In Fig. 5a, the images inverted with combined networked 2D and 3D data in WNLPA show the two vertical conductive conduits of craters $B$ and $S$, yet the image inverted with only $2 \mathrm{D}$ data does not illustrate the vertical structures correctly. The forward simulation has a similar result as what we obtained from the field WNLPA surveys. Therefore we conclude the approach to combine the 2D and 3D data can yield an image with good resolution of the conductive structures in WNLPA.

\section{DISCUSSION}

In the study, the data of 3D looped surveys are much noisier than that of the $2 \mathrm{D}$ data. Table 1 is a list of the inversion root-mean-square (RMS) and L2-norm of different datasets from the WNLPA surveys. In Table 1, inversions of 3D looped data are noisy such that a large portion of data is removed in the pre-processing procedures. In addition, the inversion of 3D looped data has much higher RMS than the inversion of 2D networked data. One possible reason for the noisy 3D looped data is that the electrodes in the looped surveys are aligned in a loop and the Dipole-dipole and Wenner measuring sequence is used in this study. It results in extraordinarily high or even negative geometric factors for some measurements in the 3D data. For instance, the geometric factor varies between 10179 and 28 in our 2D surveys, and varies between 26707 and -9712 in the 3D looped surveys. Because the apparent resistivity $\left(\rho_{a}\right)$ and measured potential difference $(\Delta V)$ follows the relationships:
$\rho_{a}=K \cdot \frac{\Delta V}{I}$

where $K$ represents the geometric factor. For a given homogeneous half-space model, if the value of the geometric factor is twice, the measured potential difference will be half of the original value. It means the some potential differences measured in the 3D looped surveys will be much more less than that in the 2D surveys, and the data are prone to the background noises since we used the same measuring equipment designed for standard 2D surveys.

To analyze how the background noises affect the inversion of 2D and 3D data differently, we used the WNLPA simulation model and added a random background noise to compare the inversion results from different datasets and approaches. The measured resistances (i.e., $\Delta V / I)$ in $\mathrm{WN}$ LPA are above $0.0001 \mathrm{Ohm}-\mathrm{m}$, therefore we tried to add a moderate noise between $0.0001 \mathrm{Ohm}$ and $-0.0001 \mathrm{Ohm}$ into the synthetic data from the forward modeling. In addition, we also tried to remove the data with apparent resistivity below $1 \mathrm{Ohm}-\mathrm{m}$ and above $12 \mathrm{Ohm}-\mathrm{m}$ in the pre-processing procedure for the synthetic dataset to test if the cut-off approach as that we did for the WNLPA field data could improve the inversion. Table 2 shows a comparison of inversion with different datasets and approaches. In Table 2 , the RMS is about $4.9 \%$ and $5.1 \%$ for the inversions with simulated networked 2D and 3D looped datasets, respectively. If the background noises are added into the datasets, the RMS is increased to about $6.3 \%$ for the inversion with networked 2D data, and is increased to about $10.2 \%$ for the inversion with only 3D looped data. Note, the L2 norm increases slightly from about $0.8 \sim 0.9$ to $1.1 \sim 1.2$ after the background noises are added. If we use the pre-processing filter to remove the data with apparent resistivity below $1 \mathrm{Ohm}-\mathrm{m}$ and above $12 \mathrm{Ohm}-\mathrm{m}$, the RMS of the inversions with 2D data and 3D looped data are decreased to about $5.8 \%$ and $6.5 \%$, respectively. Note, the L2-norm is about the same for both inversions of $2 \mathrm{D}$ and $3 \mathrm{D}$ datasets after the filtering approach is conducted. The test indicates that the same background noises have larger influences on the 3D looped measurements than the 2D networked measurements. And the approach that removed data with far-off apparent resistivity is practical in reducing the RMS of the inversion.

\section{CONCLUSION}

In this study, we have tried to use the combined 2D networked and looped 3D measurements to image the subsurface fracture systems of the mud volcanoes in WNLPA. We conducted 2D resistivity surveys along seven networked lines to provide a global perspective regarding the WNLPA's resistivity structures. In addition, we adopted a looped 3D electrode array that surrounds each mud-volcano crater 
(a)

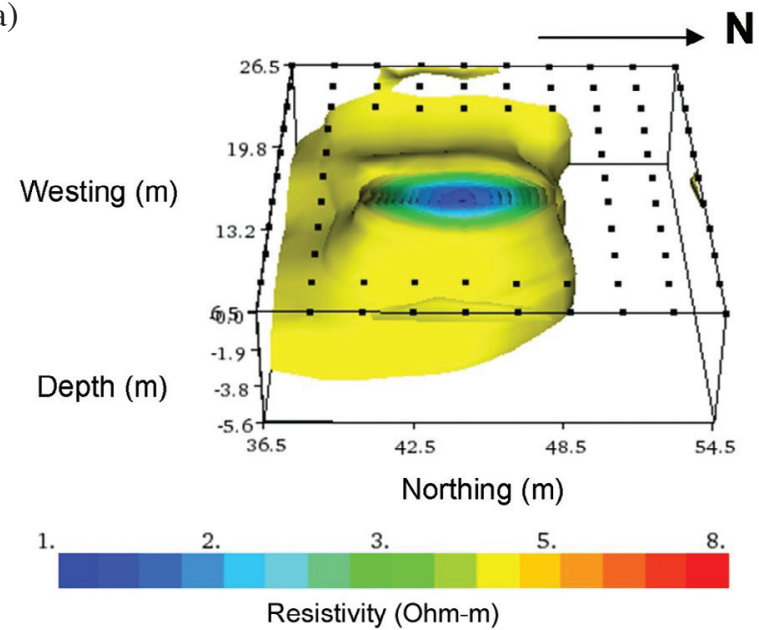

(b)

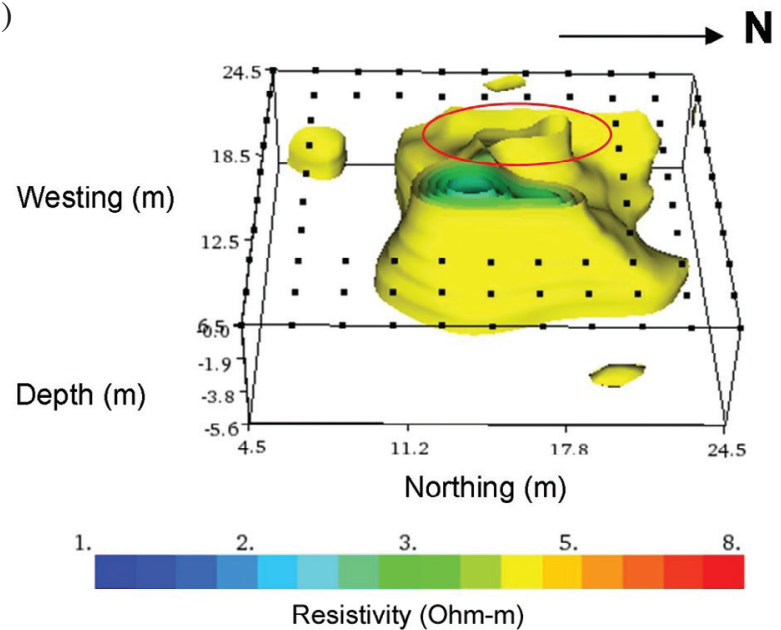

Fig. 11. (a) The image inverted with only the 3D looped measurements of mud volcano B's crater from the forward simulation results. (b) The image inverted with only the 3D looped measurements of mud volcano $\mathrm{S}$ 's crater from the forward simulation results.

Table 1. Comparison of inversion with different datasets collected in WNLPA.

\begin{tabular}{lccc}
\hline Data used & data removed percentage & normalized L2 norm & RMS \\
\hline networked 2D data (WNLPA) & $3.0 \%$ & 0.5 & $5.0 \%$ \\
looped 3D from Crater S (WNLPA) & $14.6 \%$ & 1.0 & $13.6 \%$ \\
looped 3D from Crater B (WNLPA) & $63.5 \%$ & 4.8 & $32.4 \%$ \\
2D and 3D data (WNLPA) & $20.4 \%$ & 0.9 & $8.3 \%$ \\
\hline
\end{tabular}

Table 2. Comparison of inversion with different datasets and approaches from the forward simulation.

\begin{tabular}{|c|c|c|c|}
\hline Data used & Removed percentage & normalized L2 norm & RMS \\
\hline networked 2D data & $0.0 \%$ & 0.8 & $4.9 \%$ \\
\hline looped 3D data from Crater B & $0.0 \%$ & 0.9 & $5.1 \%$ \\
\hline networked 2D data with moderate error added & $0.0 \%$ & 1.1 & $6.3 \%$ \\
\hline looped 3D data from Crater B with moderate error added & $0.0 \%$ & 1.2 & $10.2 \%$ \\
\hline "filtered" networked 2D data with moderate error & $0.5 \%$ & 1 & $5.8 \%$ \\
\hline "filtered" looped 3D data from Crater B with moderate error & $5.5 \%$ & 1.2 & $6.5 \%$ \\
\hline
\end{tabular}

to capture images of the expected conductive mud conduits. Although the looped 3D surveys roughly reveal two conductive regions under the two major mud volcanoes, the locations of the conductive regions are inconsistent with the observed surface positions of the mud volcano craters. We further combined the 2D networked and looped 3D measurements and inverted the data for building a comprehensive resistivity model of WNLPA. The resulting image shows one distinctive vertical conductive body at the location of mud volcano B, and reveals two split conductive channels at mud volcano $\mathrm{S}$. The combined image is consistent with the locations of the observed surface landscapes and the GPR exploration results. With the 3D resistivity images, we tried to estimate the water-content distribution in terms of the "water content"-resistivity relationships from the laboratory test. The estimated results show a flat groundwater surface 
and vertical over-saturated conduits. The results suggest that it is possible to capture images of dual porosity structures with 3D high-resolution resistivity surveys.

In addition, we used a simplified WNLPA model for forward simulation, in order to verify our inverted results. The images of simulated 3D looped surveys show that artifacts may appear in such images if there are unaccountedfor conductive structures outside the electrode array loops. Because we observed that the WNLPA features are composed of many conductive mud conduits, the 3D inversion results may contain these conductive objects' shadow effects, similar to the effects resulting from such 2D cases as discussed in Nimmer et al. (2008). In addition, 2D networked measurements can contribute to the formation of a global resistivity model, yet the 3D looped data can yield further information about the structures' details. As a result, we are currently using a combination of 2D and 3D resistivity surveys to monitor the variation of the mud conduits.

Acknowledgements The authors would like to thank the National Science Council of the Republic of China for supporting this research under Contract No. NSC 95-2116-M041-002 and NSC 96-2116-M-041-002.

\section{REFERENCES}

AGI, 2008: Instruction Manual for EarthImager 3D version 1.5.3, Advanced Geosciences, Inc., Austin, Texas, $99 \mathrm{pp}$.

AGI, 2009: Instruction Manual for EarthImager 2D version 2.4.0. Advanced Geosciences, Inc., Austin, Texas, $139 \mathrm{pp}$.

Archie, G., 1942: The electrical resistivity $\log$ as an aid in determining some reservoir characteristics. Petrol. Trans., AIME, 146, 54-62.

Bernstone, C., T. Dahlin, and P. Jonsson, 1997: 3D visualization of a resistivity data set-an example from a sludge disposal site. Symp. Appl. Geophys. Eng. Environ. Probl., Procs., Reno, Nevada, March 23-26 1997, Vol. 2, 917-925.

Cassiani, G., V. Bruno, A. Villa, N. Fusi, and A. M. Binley, 2006: A saline trace test monitored via time-lapse surface electrical resistivity tomography. J. Appl. Geophys.,59,244-259, doi: 10.1016/j.jappgeo.2005.10.007. [Link]

Chang, P. Y., T. Y. Yang, L. L. Chyi, and W. L. Hong, 2010: Electrical resistivity variations before and after the Pingtung earthquake in the Wushanting mud volcano area in southwestern Taiwan. J. Environ. Eng. Geophys., 15, 219-231, doi: 10.2113/JEEG15.4.219. [Link]

Cheng, P. H., Y. I. Ger, and S. L. Lee, 2008: An electricresistivity study of the Chelungpu fault in the Taichung area, Taiwan. Terr. Atmos. Ocean. Sci., 19, 241-255, doi: 10.3319/TAO.2008.19.3.241(T). [Link]

Chow, J. J., S. K. Chang, and H. S. Yu, 2006: GPR reflection characteristics and depositional models of mud volcanic sediments - Wushanting mud volcano field, southwestern Taiwan. J. Appl. Geophys., 60, 179-200, doi: 10.1016/j.jappgeo.2006.03.001. [Link]

Constable, S. C., R. L. Parker, and C. G. Constable, 1987: Occam's Inversion: A practical algorithm for generating smooth models from electromagnetic sounding data. Geophysics, 52, 289-300, doi: 10.1190/1.14423 03. [Link]

Dahlin, T., 1996: 2D resistivity surveying for environmental and engineering application. First Break, 14, 275-283.

Dahlin, T. and M. H. Loke, 1997: Quasi-3D resistivity imaging - Mapping of three dimensional structures using two dimensional DC resistivity techniques. Procs. $3^{\text {rd }}$ Meeting Environmental and Engineering Geophysics, Aarhus, Denmark, 8-11 September 1997, Expended Abstracts, 143-146.

Dahlin, T., C. Bernstone, and M. H. Loke, 2002: A 3-D resistivity investigation of a contaminated site at Lernacken, Sweden. Geophysics, 67, 1692-1700, doi: 10. 1190/1.1527070. [Link]

Daily, W., A, Ramirez, D. LaBrecque, and J. Nitao, 1992: Electrical resistivity tomography of vadose water movement. Water Resour. Res., 28, 1429-1442, doi: 10.1029/91WR03087. [Link]

deGroot-Hedlin, C. and S. Constable, 1990: Occam's inversion to generate smooth, two-dimensional models from magnetotelluric data. Geophysics, 55, 1613-1624, doi: 10.1190/1.1442813. [Link]

Dey, A. and H. F. Morrison, 1979: Resistivity modeling for arbitrarily shaped three-dimensional structures. Geophysics, 44, 753-780, doi: 10.1190/1.1440975. [Link]

Huang, Y. L., L. S. Teng, C. S. Liu, N. Lundberg, and D. Reed, 1992: Structural styles of offshore southwestern Taiwan. Eos, Trans., AGU, 73, p. 539.

Keng, W. P., 1981: Geologic map of Tainan Hills. Bull. Cent. Geol. Surv., 1, 1-31. (in Chinese)

LaBrecque, D., D. L. Alumbaugh, X. Yang, L. Paprocki, and J. Brainard, 2002: Three-dimensional monitoring of vadose zone infiltration using electrical resistivity tomography and cross-borehole ground-penetrating radar. Methods Geochem. Geophys., 35, 259-272, doi: 10.1016/S0076-6895(02)80097-X. [Link]

Lippmann, E., 2005: 4-point light hp technical data and operating instructions, ver. 3.37, Geophysikalische Messgerate, Schaufling, Germany, $28 \mathrm{pp}$.

Liu, C. S., I. L. Huang, and L. S. Teng, 1997: Structural features off southwestern Taiwan. Mar. Geol., 137, 305319, doi: 10.1016/S0025-3227(96)00093-X. [Link]

Loke, M. H. and R. D. Barker, 1996: Practical techniques for 3D resistivity surveys and data inversion. Geophys. Prospect., 44, 499-523, doi: 10.1111/j.1365-2478.19 
96.tb00162.x. [Link]

Loke, M. H., I. Acworth, and T. Dahlin, 2003: A comparison of smooth and blocky inversion methods in 2D electrical imaging surveys. Explor. Geophys., 34, 182-187.

Nimmer, R. E., J. L. Osiensky, A. M. Binley, and B. C. William, 2008: Three-dimensional effects causing artifacts in two-dimensional, cross-borehole, electrical imaging. J. Hydrol., 359, 59-70, doi: 10.1016/j.jhydrol. 2008.06.022. [Link]

Shih, T. T., 1967: A survey of the active mud volcanoes in Taiwan and a study of their types and the character of the mud. Petrol. Geol. Taiwan, 5, 259-311.

Slater, L., A. Binley, R. Versteeg, G. Cassiani, R. Birken, and S. Sandberg, 2002: A 3D ERT study of solute transport in a large experimental tank. J. Appl. Geophys., 49, 211229, doi: 10.1016/S0926-9851(02)00124-6. [Link]
Wang, S. H., L. Mei, and C. F. Yang, 1988: Mud volcanoes of Taiwan. Ann. J. Taiwan Museum, 31, 31-49.

Yang, C. H., P. H. Cheng, J. I. You, and L. L. Tsai, 2002: Significant resistivity changes in the fault zone associated with the 1999 Chi-Chi earthquake, west-central Taiwan. Tectonophysics, 350, 299-313, doi: 10.1016/ S0040-1951(02)00146-4. [Link]

Yang, C. H., C. Y. Yu, T. R. Guo, and J. Y. Tsaur, 2005: Verification of the suspected Tachia-tung Fault by ground penetrating radar and resistivity image profiling methods. Terr. Atmos. Ocean. Sci., 16, 10451059.

You, C. F., J. M. Gieskes, T. Lee, T. F. Yui, and H. W. Chen, 2004: Geochemistry of mud volcano fluids in the Taiwan accretionary prism. Appl. Geochem., 19, 695-707, doi: 10.1016/j.apgeochem.2003.10.004. [Link] 